\title{
COMUNICACIÓN Y CREACIÓN DE ARQUETIPOS
}

\author{
Fernando de la Hermosa Serrano \\ Ingeniero MBA
}

\section{Resumen:}

Desde que el hombre es hombre y ha tenido capacidad de comunicación, ha utilizado esta, simultáneamente con otras herramientas, para generar corrientes de opinión, despertar simpatía, promover el odio o el miedo, a su favor y contra oponentes y adversarios. Fundamentalmente dicha labor se ha llevado a cabo atribuyendo determinadas características físicas y mentales al personaje objeto de la animadversión, que contribuían a crear una determinada imagen en el inconsciente colectivo, que en muchos de los casos y situaciones se ha comprobado falsa y mendaz y a pesar de esto, ha resultado imposible corregir o limpiar aún comprobándose la manipulación, incluso documentalmente.

El dicho español "tu calumnia que algo queda", nos sirve para mostrar cómo a lo largo de la historia, grandes personajes, independientemente de su poder e influencia (o precisamente por esto) han sido arrastrados por el fango, generándose una imagen y reputación que luego ha sido casi imposible contrarrestar a pesar de la labor de investigación llevada a cabo por historiadores que ha venido a demostrar lo contrario. Sin embargo, la manipulación de la imagen de una persona no sólo se adscribe al ámbito del poder y la influencia, el ser humano se ha aprovechado de la difamación en todos los ámbitos sociales en su beneficio, aunque a veces esto podía llevar al extremo las consecuencias de tal actuación.

Palabras clave: Arquetipo - Intereses - Confusión - Parcialidad - Imagen

\section{INTRODUCCIÓN}

Desde finales del siglo XVI, Felipe II ha sido considerado por muchos historiadores como "un hombre cuya maldad y doblez" eran casi sobrehumanas, "sin la más mínima virtud", un "redomado hipócrita", en la vida privada y "un tirano" en la vida pública. En 1558, es presentada la vida del rey como una obra de teatro, (la narración se efectúa en cinco actos), con una parcialidad poco cuestionable, en la que resulta difícil encontrar un solo soplo de aire limpio en el huracán que azota la figura del heredero del Emperador Carlos. Estas afirmaciones de Moley no eran gratuitas; Guillermo de Orange, jefe de la República Holandesa, llegó a acusar al Rey de lujurioso, -hasta el límite de haber cometido incesto- y, entre otras maldades, de haber asesinado a su hijo mayor. El que fuera su secretario, Antonio Pérez, tras su caída, encarcelamiento y huída posterior, "se despacha a su gusto", como diría un madrileño de la corte de la época (que no cortesano), en sus "relaciones", dando un retrato del Rey muy poco halagador. Todos los estudios que se efectuaron posteriormente sobre la vida y figura de Felipe II estarán definitivamente marcados por los comentarios y anécdotas que se recreaban con estas obras. 
Las investigaciones realizadas por el profesor Parket de la Universidad de Illinois (Estados Unidos) han puesto de manifiesto la "creación" de una imagen de Felipe II muy alejada de la verdadera, demostrando, incluso, que los documentos originales de Antonio Pérez habían sido falsificados en algunas partes y que todos los párrafos que calumniaban al Rey habían sido interpolados. Pese a ello, la imagen creada aún perdura en muchos países centroeuropeos.

"El hombre debe ser negro, viejo, rijoso, maloliente, gigantesco, con alguna malformación. También puede ser muy moreno y barbudo, con la nariz deforme, al menos muy aguileña. La boca ha de estar abierta y muy rasgada. Los ojos han de ser brillantes y muy hundidos, manos y pies ganchudos como los de los animales, brazos y muslos pelados y delgados, piernas de asno o de cabra, pies como pezuñas y contrahechos : ¡EL DEMONIO!. El macho cabrío, en quien San Jerónimo veía el símbolo de la lujuria (el "pilosus" profético); el número de la bestia o del maligno 666, etc., etc. son representaciones constantes de quien, estimo sin afirmarlo, pocos han podido ver más allá de una situación algo o muy alucinada, o "extasiada" al menos. Tenemos, no obstante, su imagen más o menos creada con cierta intención. El dios Pan, o los sátiros, nada tienen que ver con ella... ¿O sí?.

En 1563, Calvino decidió castigar a todas las brujas fueran "buenas o malas". El que pudieran curar "las buenas" por procedimientos no reconocidos por los "doctores" era un síntoma de extrañas alianzas, puesto que las brujas no sólo son herejes, lo que tiene fácil redención, sino "endemoniadas" con las que nada pueden hacer los exorcistas al serlo por propia voluntad. Todo nacería en 1484 con la promulgación por Inocencio VIII de la bula SUMMIS DESIDERATE; apenas dos años después el "martillo de brujas" definiría finalmente la "idea" de una bruja y cómo perseguirla. La pasión carnal insaciable, por ejemplo, las llevaba a tener relaciones carnales con el demonio, claro está que en el Concilio de Basilea (1435-1437) se decidió eliminar a las brujas, y todo con base en un panfleto de Juan Nider, (el fornicarius), que resumía las confesiones de endemoniados a los jueces inquisidores suizos. Basándose en confesiones fantásticas -el juez "conocía la verdad" y la buscaba con todos sus medios- se transformaba en brujas a inocentes víctimas que sólo representaban "intereses" vengativos de una estructura feudal en que la Iglesia y el Estado necesitaban culpables entre aquellos que mantenían sus creencias ancestrales, o que se enfrentaban a una sociedad corrupta y que ignoraba la evolución creativa del pensamiento. Había que crear una "imagen" y se creó. Verlaine diría después: "ya no hay brujas porque no se quema".

Podríamos recurrir a un número de ejemplos y casos que harían interminable esta exposición. Tan sólo se ha pretendido avanzar en una idea; cual es que la acumulación de anécdotas y su utilización de forma más o menos intencionada propone un modelo más inteligible, más claro, aunque con frecuencia encubra y transforme a un ser real más atrayente y humano del que crea el "arquetipo".

\section{MODELO Y ARQUETIPO: SU UTILIZACIÓN Y CONFUSIÓN}

Las anécdotas que se atribuyen a muchos personajes históricos han sido creadas o aplicadas a otras personas que nacieron mucho antes de aquél a quien luego se le 
atribuyen. La historia y la literatura dan una buena prueba de ello. Este tipo de anécdotas y su utilización "por tener algo más de ciertas", hacen que puedan aumentarse las virtudes o maldades de un personaje histórico como se ha hecho en varias ocasiones. Las anécdotas "conforman" un carácter, o cuando menos se puede recrear el carácter con anécdotas intencionadas. Así puede crearse un arquetipo y del arquetipo al bulo sólo hay un paso consciente o inconsciente; pero volveremos sobre ello después de aclarar algunos conceptos.

La palabra griega arquetipo se usa en castellano no con la antigüedad que algunos pretenden. El Diccionario Histórico de la Lengua Castellana de la Real Academia, (Madrid, 1955) nos enseña que a partir del XIX Juan Valera comentará la "belleza arquetípica" de una mujer, y Campoamor lo utilizará en un sentido filosófico. Define, por tanto, una idea general que reúne varios ejemplares y en nada a una individualidad. Un arquetipo, en suma, es un modelo común. En mecánica y astrología era utilizado en la ciencia helenística de esta forma; escritos latinos mantienen una misma acepción (Cicerón, Epístola a Ático); sin embargo, el castellano utiliza la palabra modelo -mucho más arraigada- como algo creado con el fin de copiarlo a una mayor escala, como norma que sirve de ejemplo, como algo que se propone para ser ejecutado, que se imita o evita, etc. El arquetipo, en definitiva, se obtiene sin una clara intervención de la voluntad y se forma por distintas vías o alternativas, mientras que el modelo es conscientemente creado. Importante diferencia.

La utilización, o en su caso, la representación arquetípica, se constituye y usa de un modo poco claro y puede ser laudatoria o maledicente, obteniéndose con juegos retóricos y resultando así casi contradictoria pero trascendente. La malignidad individual o colectiva es fuente de muchos arquetipos, y una vez creados se usan en momentos y circunstancias que, a nivel individual o colectivo, son consideradas "oportunas" para el usuario intencionado. Es en estos casos cuando el arquetipo se utiliza como modelo con una intención oscura, y ya hemos visto la notable diferencia entre ambos conceptos.

Un "modelo individual", creado por un grupo o clase social determinada (con caracteres positivos) o el modelo creado por sus rivales (con caracteres negativos) acaba constituyéndose en un arquetipo que es utilizado, incluso, por personas y grupos que no tienen nada en común con aquellos., recreando los relatos de unos y otros según convenga a la mayor o menor aproximación del relator. Es entonces cuando el "se dice, se comenta, lo sé de buen a tinta" transforma un posible arquetipo en bulo, además crece y enriquece el primer arquetipo creado, ya sea para bien o mal, porque la utilización del arquetipo siempre está cargada de ciertos "tintes" de verosimilitud, lo que hace indefectiblemente que la búsqueda de la verdad no sea siempre tan sencilla y el "bulo" repetitivo acaba teniendo base en circunstancias y hechos anteriores que con pretendido rigor se anuncian como ejemplo (.... ya ocurrió algo parecido con don Fulano, en tal año pasó lo mismo y los responsables Rieron ellos, etc.) por pretendidos historiadores o retóricos de medio pelo.

El arquetipo procura, perfeccionar, perfilar, aclarar, representar algo, a alguien, o a un colectivo, que no es tan perfilable; en esos instantes la búsqueda de la 
"referencia", el "precedente", la "cita erudita", etc., constituyen las bases en las que el arquetipo inicial irá creciendo en múltiples desdoblamientos generando una imagen que, en suma, en nada corresponde a la realidad. En el uso y abuso del arquetipo se basan con inusitada frecuencia las justificaciones y posiciones contrarias a la verdad y a la razón, y lo escrito con anterioridad no es ajeno a ello.

Modelo- arquetipo- bulo- arquetipo/mito -destrucción del modelo primigenio arquetipo recreado -personalización -mitogenia-nuevo modelo..., y así nacerá un arquetipo histórico tan comúnmente aceptado que será difícil, fuera de los ámbitos científicos, demostrar su inexactitud (porque los españoles somos Quijotes y Sanchos, Don Juanes, machistas, perezosos, etc...). El arquetipo individual se generaliza y el general se individualiza, en una exageración tipificante según convenga en cada caso. Todo dependerá del arquetipo escogido, que los hay variopintos, según se individualice o generalice y el resultado será el apetecido.

Lo hasta aquí expuesto cobra importancia decisiva cuando entramos en el campo de lo legendario. La tradición oral y la iconografía son a veces soportes de leyendas contadas con "talante histórico" y crean arquetipos por traslación y tipificación a perfiles de personas o a grupos ajenos por completo al origen de la leyenda. La hagiografía cristiana está cargada de múltiples ejemplos. El relato ejemplar no es en ocasiones más que la utilización de un arquetipo para hacer más inteligible a los fieles la vida de un santo, o justificar actuaciones "menos santificables", por el bien de la Iglesia o la salvación de las almas.

La comprobación histórica de un relato no es siempre fácil (Napoleón es un genio militar para historiadores franceses y un estúpido para Tolstoi); las anécdotas creadoras del arquetipo están unidas a pretendidas "verdades" y a "comparaciones oportunas" con otros genios de la Historia; y así con todo y con todos; y así, hasta hoy...

Considero, para terminar, y en próxima ocasión he de volver sobre ello, que la narración arquetípica aunque sea laudatoria encierra malignidad, por cuanto puede llegar a confundir a aquéllos que, como mantiene Julio Caro Baroja, en múltiples escritos se conforman con lo verosímil y dejan atrás la verdad. Modelo y arquetipo no deben confundirse y menos si éste está construido con bulos (concebidos como noticias falsas). A veces, los "rumores legalizados" colaboran también en la creación del arquetipo. Pero, esto es motivo de la segunda parte del artículo. 